\title{
PARENTAL PERCEPTION OF LOW IQ FACTS OR FICTION: RETROSPECTIVE DATA FROM CLINIC IN SEMI RURAL MAHARASHTRA
}

\author{
Dr. Suchit Suresh Tamboli, Dr. Charudatt Joglekar, Dr. Vasant Desle, Dr. Anvesh Tamboli \\ Chiranjiv Clinic, Child development and Research Institute, Ahmednagar, Maharashtra, India.
}

\section{ABSTRACT}

Objective: To study the association between physical and psychological problems perceived by parents and the IQ of their children. Methods: We studied 981 children in the child development center at Ahmednagar. Median age at followup was 7.8y $\left(\mathrm{Q}_{25}=5.6 \mathrm{y}\right.$ and $\mathrm{Q}_{75}=10.4 \mathrm{y}$, Babies underwent IQ evaluation by Binet Kamat scale $(\mathrm{n}=981)$; also their physical and psychological problems perceived by parents were documented. We categorized children into 4 categories using number of problems (physical and psychological separately) viz 1 (no problem), 2 (1 problem), 3 (2 problems), 4 (>2 problems). When we looked at physical problem data, 555 (56.6\%) had no problem, $251(25.6 \%)$ had $1,117(11.9 \%)$ had 2, and remaining $58(5.9 \%)$ had more than 2. For psychological problems like not interested in studies, speech problems don't remember, don't understand, cannot concentrate, fears, etc. The distribution was 221 (22.5\%), $212(21.6 \%), 222(22.6 \%)$ and $326(33.3 \%)$ respectively. Result: The increasing trend of mean IQ for physical problem parameters from nil to $>2$ categories and decreasing prevalence of low IQ using Binet Kamat scale were not significant. However, for psychological problems the decreasing and statistically significant trend $(\mathrm{p}=0.000)$ was present for mean IQ, and a significant increasing trend $(\mathrm{p}=0.029)$ for prevalence of low IQ was observed. Conclusion: Psychological problems were associated with IQ. Numbers of problems were inversely correlated with IQ.

Keywords: Parental Perception; Low IQ; Behavioral Problems; Physical Problems.

\section{INTRODUCTION}

Parents present with physical or psychological problems; some of these problems need attention and workup, and other issues need only counseling. Early detection of physical and psychological problems that need intervention should be identified by pediatricians in his OPD. He should understand the problems who need only counseling and the problems who need intervention and therapies. Early intervention helps in prevention of disability. It gives environment to use full potential of the child.

All children of NICU should get training from birth to prevent physical and psychological problems. Training can be given considering mother as a therapist of the child. She was given help by therapist when needed. The stimulation program given at birth reduces abnormalities by $40 \%$.

Developmental Observation Card (DOC) is a simple screening tool by Dr. M.K.C. Nair, In this tool we have to check that baby has social smile at 2 months, holds his neck at 4 months, sits alone by 8 months, stands at 12 months, utters ba-ba, da-da, and ma-ma by 12 months and also he understands our language at 12 months. If child is not doing according to this chart he/ she must be shown to pediatrician for further workup.

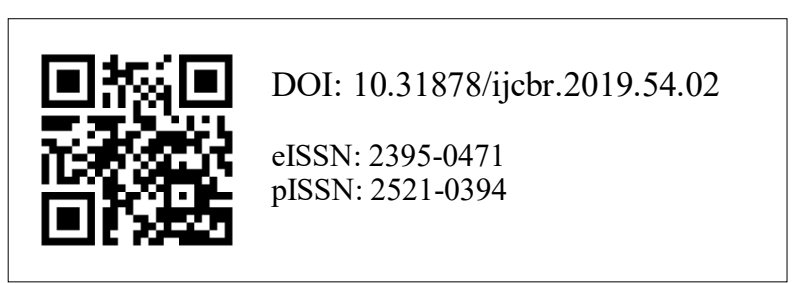

Age-wise screening tools like Devnver Scale for 0-6 years, Draw a man test, etc. can be used for early detection. Physical illnesses like Anemia, Asthma, Urinary Tract Infection, Pain in Abdomen, Headache, etc. can affect Growth and Development. Scholastic Backwardness, Phobia Anxiety, Learning Disorders, Behavioral Problems, etc. are important psychological problem which affects performance of the child.

\section{Factors Influencing School Performance:}

Home-related factors: Factors that hinder school performance are Parental illiteracy, lack of encouragement and lack of role models, alcoholic and workaholic parents, contribute to academic performance $[1,2]$.

The school-related factors: The child spends most of his time in school, and here his environment is exerting a different influence on performance through curricula, teaching techniques, relationships [3, 4].

Child-Teacher Relationships: A growing body of evidence supports this claim as child-teacher attachment relationships are essential for children's social and emotional development [5].

The psychological factors: Psychosocial factors (PSFs) such as motivation, social control, and self-regulation, play critical roles in classroom learning [6]. The motivation to achieve academic outcomes in educational settings via specific personality characteristics and attitudes will bring the desired outcome in scholastic performance [7].

Disease-related factors: These conditions have been

Correspondence: Dr. Suchit Suresh Tamboli, Chiranjiv Clinic, Child development and Research Institute, Ahmednagar, Maharashtra, India. Email: tamboli.k@gmail.com 
reported to have an independent effect resulting in scholastic performance.

Visual impairment: worsening in handwriting and slowness in copying from the board.

Hearing Impairment: Even mild to moderate hearing loss in childhood is associated with poor language development and lower educational achievement.

Objective: To study the association between Physical and Psychological problems perceived by parents and low IQ of their children.

\section{MATERIAL AND METHODOLOGY}

Study design: Correlation Study.

Ethics approval: The study was approved by Chiranjiv Clinic Child Development and Research Institute Ethics Committee, and informed consent was taken from the parents.

Study location: Chiranjiv Child Development and Research Institute, Ahmednagar.

Inclusion criteria: Physical problems which affects school or home environment, psychological problems which affects school or home environment, parental concern about physical and mental problems told while attending OPD for illness or vaccinations, parental concern about intelligence and performance of a child.

Exclusion criteria: Emotional and psychosexual problems, those who lost for follow up to subsequent visits more than 3 , parents who are not ready to give home-based stimulation program

Sample size: 1153 children included in the study by random sampling

Physical and psychological problems were stratified into four groups.

- Group1: no problem,

- Group 2: 1 problem,

- Group 3: =2 problems,

- Group 4: 3 or more problems

The method used for all problems presented was an intelligence test named Binet Kamat Test. This test is standardized 2 decades back on Indian children. This test measures mental age by pass or fails of items given for that age.

This test gives abilities in the following areas: -

1. Comprehension of verbal instructions

2. Verbal expression of thoughts

3. Abstract thinking and reasoning

4. Serial Memory

5. Form Perception

6. Knowledge of concepts like shape, size (big / small), length (short / long), weight (heavy / light), direction (left / right), gender (boy / girl) etc.

IQ is measured by formula (mental age / chronological age * 100). IQ $90-110$ is considered normal, and IQ range $70-90$ is a slow learner or borderline and IQ 50
- 70 is called as Mild Mental Retardation.

Statistical Analysis: Analysis of variance was used to test trend in mean IQ across 4 groups, Chi-square test was used to test the trend in the proportion of those with low IQ across groups, Odds ratios for low IQ for each group in relation to those with a group with no problems were calculated by logistic regression. $95 \%$ confidence intervals were calculated.

\section{RESULTS}

Table 1: Demographic data $(n=1153)$

\begin{tabular}{|c|c|c|}
\hline & $\mathbf{n}$ & N (\%) \\
\hline Gender & 1153 & $\begin{array}{l}\text { Boys } 773(67 \%), \\
\text { Girls } 380(33 \%) \\
\text { High: } 50(5.5 \%)\end{array}$ \\
\hline Social class & 907 & $\begin{array}{l}\text { Middle: } 804(88.6 \%) \\
\text { Lower: } 47(5.2 \%) \\
\text { Slum: } 6(0.7 \%)\end{array}$ \\
\hline Consanguinity & 946 & $\begin{array}{l}\text { Yes: } 233(24.6 \%) \\
\text { No: } 713(75.4 \%) \\
\text { Nuclear: } 336(35.3 \%)\end{array}$ \\
\hline Family type & 956 & $\begin{array}{l}\text { Joint: } 465(48.7 \%) \\
\text { Extended: } 153(16.0 \%)\end{array}$ \\
\hline $\begin{array}{l}\text { Family income } \\
\text { (INR) }\end{array}$ & 902 & $\begin{array}{l}\text { Median 5000, Min-Max } \\
(300-150000)\end{array}$ \\
\hline
\end{tabular}

Physical problems: Not Eating Well, Urinary Infection, Weakness, Eyes Problem, Fever, Cold, Cough, Body ache, Breathlessness / Asthma, Pain In Abdomen, Headache, Fatness, Failure To Thrive, Constipation, Delayed Growth, Deafness, Fungal Infection, Pot Belly, Stomach Pain, Walking Problem, Joint Pain, Leg Problem, Chest Pain, No Bladder Control, Urine Problem, Frequent Urine, Puts Finger In Nose, Clenched Finger, Height Problem, Weight Problem, Illness, Hand Paresis, Drooling, Hair Fall Problem Upset, Walk-In Sleep, Rashes, Doesn't Walk Upstairs, Teeth Problem, Sleep-Related Problems, Mouth Smelling, Encoparesis, Large Head, Obesity, Myopia. Cannot Chew / Swallow, Flat Foot, Ear Problem, Excessive Swelling, Doesn't Sit Properly, Epistaxis, Falls Down Frequently, Anaemia, Neck Pain, Self Destructive, Toilet Problem, Tongue Tie, Tonsillitis, Dullness, Head Banging, Back Pain, Jumps, Squint, Low Immunity Power, Vomiting, Thalassemia, Acidity, D.N.S., Not Able To Jump, Nephrotic Syndrome, Hydrocephalus, White Hair.

Psychological problems: Scholastic Backwardness, Nocturnal Enuresis, Mental Retardation, Stubborn, Calm, Speech Problem, Seizure, Hyperactive, Stuttering, Babble Speech, Misarticulation, Thumb Sucking, Not Interested In Studies, Short Tempered Weak Memory, Shyness, Negativism, Bed Wetting, Nail Biting, Cannot Concentrate Gets Irritated, Phobia, Laziness, Does Not Understand, Does Not Remember, Cannot Remember Studies, Cannot Concentrate in Studies, Gets Angry, Slow Learner, Lying, Fears, School Phobia / Problem, Slow Movements, Aggressive, Doesn't Mix With Other Children, Does Not Have Self Confidence, Childish Behaviour, Behaviour Problems, Unstable, Less Intelligence, Reading Problem, Does Not Listen, Writing Problem, Television Addiction, Over Dependent, Nonsense Speech, Excessive Laughing, Sensitiveness, Don't Have A Friend Circle, Not Matured, Stealing Habit, Cannot See Well, Didn't Work On Time, Beating / 
Fighting Habit, Tension, Repetitions, Self Centered, Self Talking, Moody, Excessive Talk, Cannot Bath, Insecure Feeling, Doesn't Have Fear About Consequences, Unusual Expression Of Feelings, Not Interested In Playing, Destructiveness, Gets Annoyed, Sibling Rivalry, Excessive Playing, Biting Habit, Less Talk, Loneliness, Gets Confused, Doesn't Sit Properly, Disturb Others, Pica, Possessiveness, Less Brain Development, Falls Down Frequently, Reverse Nature, Excessive Crying, Turning Head, Do Not Cry, Bruxism, Inferiority Complex, Cannot Do Anything By Own, Habit Of Putting Hands In mouth, Interested In Unknown Things, Neglected Feeling, Tongue Tie, Very Quiet, Careless, Attention Deficit, get involve in elders discussion, Dislike Crowdy Places, Faithfulness, Bored, Ignored

Total numbers of Physical as well psychological problems were not associated with gender, social class, consanguinity, family type, and income.

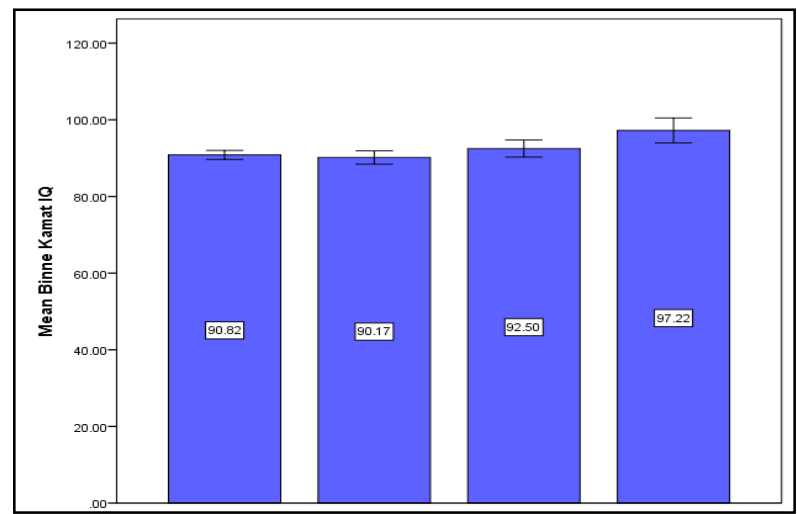

Fig 1: Physical problems and IQ by Binet Kamat $(\mathrm{n}=981)($ Mean \pm SE $)$

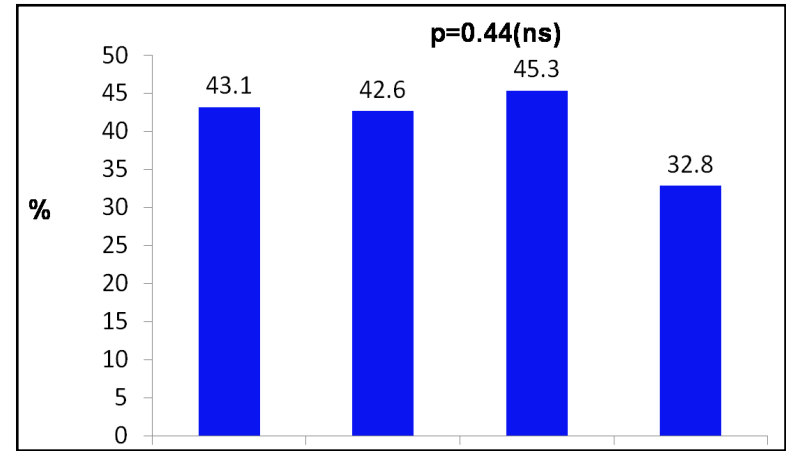

Fig 2: Physical problems and proportion of low IQ by Binet Kamat $(n=981)$

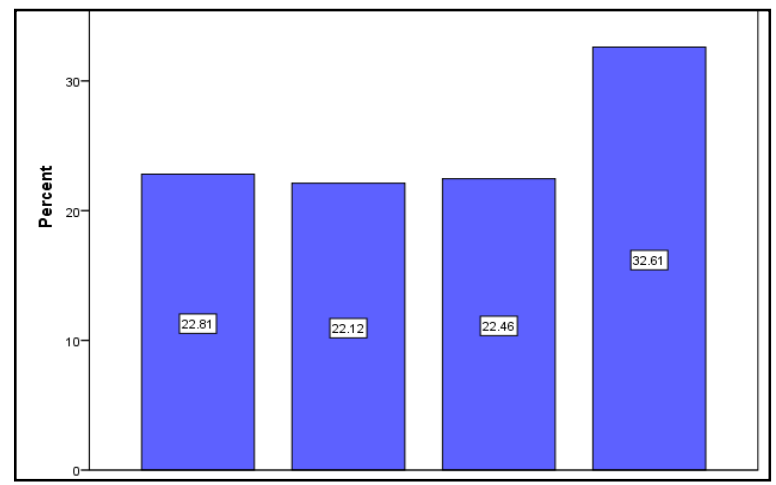

Fig 3: Distribution of Psychological problems $(n=1153)$

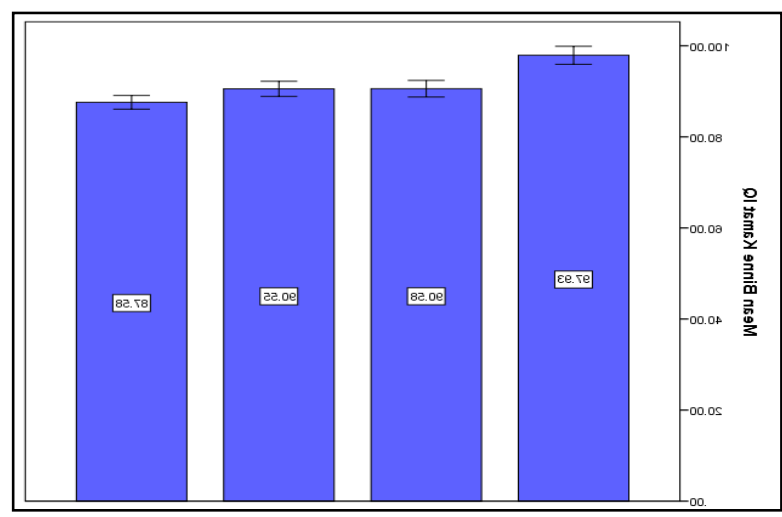

Fig 4: Psychological problems and IQ by Binet Kamat $(n=981)($ Mean \pm SE $)$

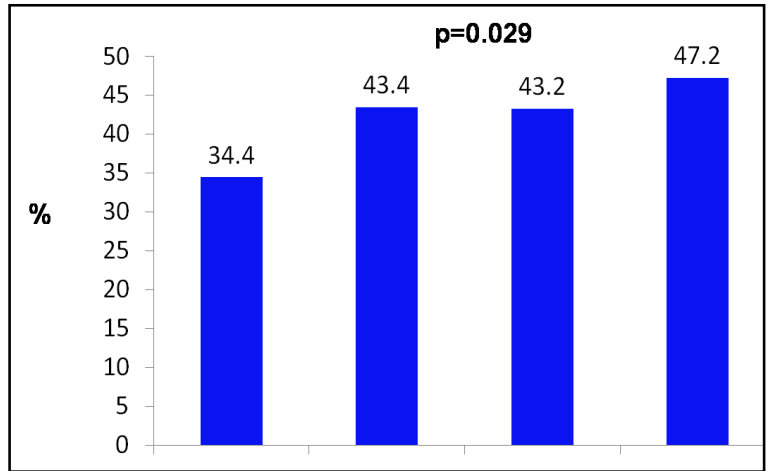

Fig 5: Psychological problems and proportion of low IQ by Binet Kamat $(n=981)$

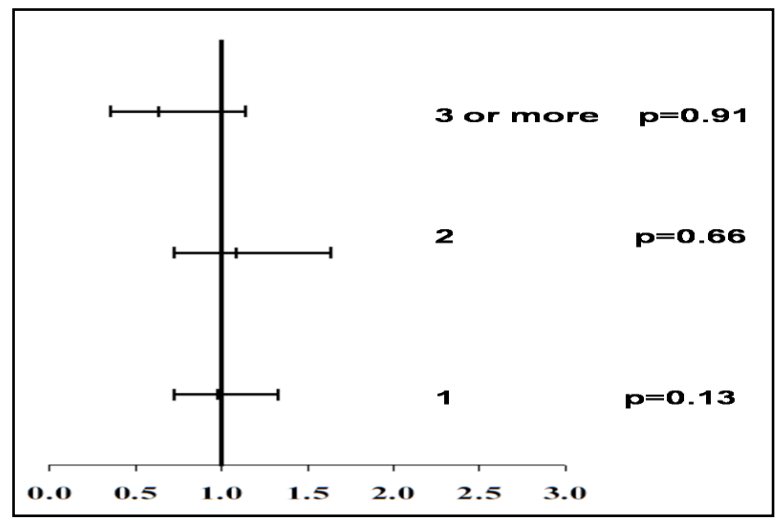

Fig 6: Risks (odds ratios with $95 \%$ CI) for low IQ For those multiple physical problems Vs No physical problems

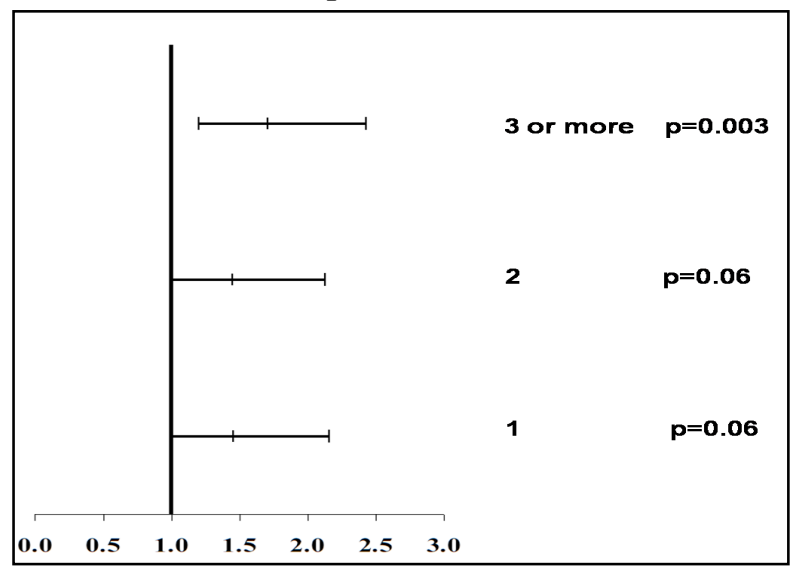

Fig 7: Risks (odds ratios with 95\% CI) for low IQ for those multiple psychological problems Vs No psychological problems 


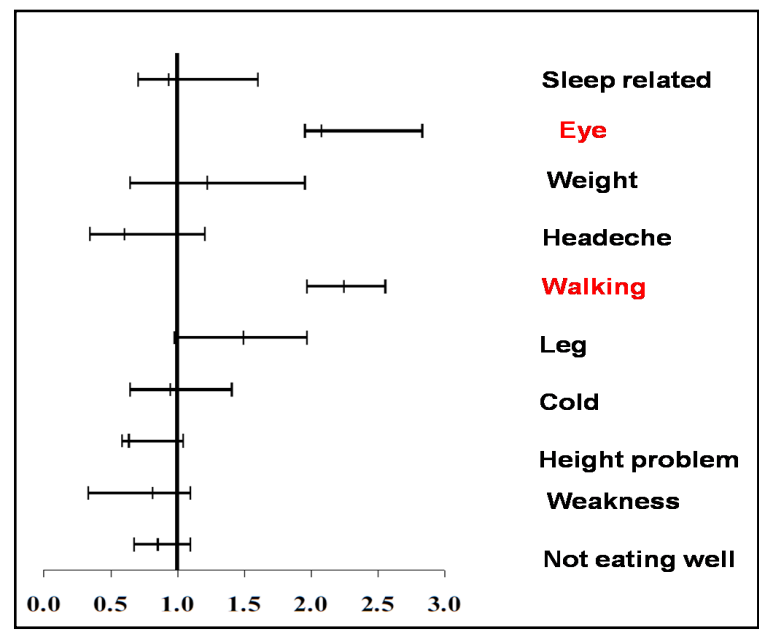

Fig 8: Risks for low IQ for specific physical problems with $95 \%$ confidence intervals

Table 2: Top 10 problems reported

\begin{tabular}{|l|l|l|l|}
\hline \multicolumn{2}{|c|}{ Physical } & \multicolumn{2}{c|}{ Psychological } \\
\hline Problem & Prevalence(\%) & Problem & Prevalence(\%) \\
\hline Not eating well & 12.5 & Lack of interestin studies & 22.4 \\
\hline Weakness & 8.9 & Stubborn & 16.1 \\
\hline Height & 3.6 & Speech & 10.3 \\
\hline Cold & 3.6 & Does not remember & 9.3 \\
\hline Leg & 3.2 & Bed wetting & 9.2 \\
\hline Walking & 2.8 & Does not understand & 6.8 \\
\hline Headache & 2.3 & Does not listen & 5.8 \\
\hline Weight & 2.5 & Stuttering & 5.3 \\
\hline Eye & 2.5 & Lack of concentration & 5.4 \\
\hline Sleep & 2.5 & Fears & 5.1 \\
\hline
\end{tabular}

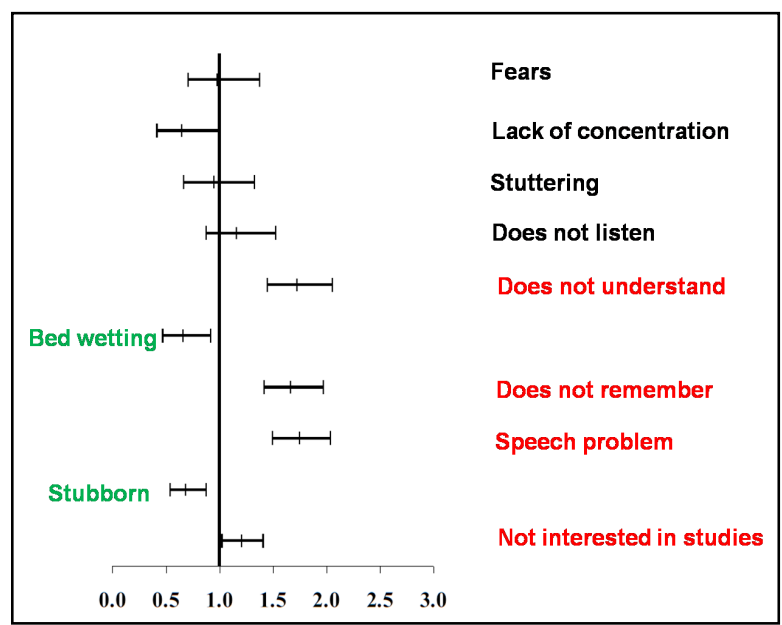

Fig 9: Risks for low IQ for specific psychological problems with $95 \%$ confidence intervals

\section{DISCUSSION}

At The etiology of child behavioral problems is complex with many interrelated factors playing an important role.
Emerging evidence suggests that individuals who score poorly on IQ tests in childhood, adolescence or early adulthood are more likely as adults to experience psychological distress ${ }^{8}$, are at increased risk of the whole range of mental disorders [8-10], and have higher rates of attempted[11, 12] and completed [13, 14] suicide. Lower IQ in children has also been associated with an increased risk of behavioral and emotional problems [15] and anxiety disorders[15, 16].

National Longitudinal Survey of Youth [17], which includes 2,256 children aged 4 to 11 , did not show any impact of maternal IQ on offspring behavioral scores in multivariable models that also included a number of factors such as family income, maternal smoking, and maternal education. However, children whose parents provided less cognitive stimulation and emotional support, as measured by poorer scores on the Home Observation for Measurement of the Environment (HOME) Inventory, had more behavioral problems.

Maternal IQ and Infant/ Toddler HOME scores obtained at 12 months made significant contributions to 3 year child IQ scores. Maternal IQ and Early Childhood HOME scores obtained at 36 months also both made significant contributions to 3 year child IQ scores [18].

Lower IQ is known to be associated with an increased risk of depression [8]. Children with epilepsy and low IQ had the most behavior problems, the lowest selfconcepts, and the most symptoms of depression [19].

There is increasing evidence that children and adolescents with lower scores on standard tests of intelligence may be more vulnerable to psychopathology later in life. Lower cognitive ability in childhood or adolescence has been associated with an increased risk of developing schizophrenia [20-23], severe depression or other nonaffective psychoses[22], posttraumatic stress disorder (PTSD) [24, 25], generalized anxiety disorder (GAD) [26], and alcohol or other drug abuse [27].

The association between early intelligence and later social adjustment is mediated by childhood conduct problems and family social circumstances. However, strong relationships exist between early intelligence and later academic achievement and income independently of these factors [28].

In our study physical problems were not associated with IQ but psychological problems more than 2 or 3 are significant and are associated with low IQ. The psychological problems which are associated with low IQ such as does not understand, does not remember, delayed speech, not interested in studies should not be taken lightly this problems need IQ testing, counseling, and intervention.

\section{CONCLUSION}

Physical problems were not associated with IQ but psychological problems were associated IQ in these children. In psychological problems, as the number of problems rises, the chances of getting low IQ are more. Few physical problems like Eye related, Delayed Walking are associated with low IQ and few psychological problems like Does not understand, Does not remember, Speech problem, Not interested in studies are associated with low IQ. Early intervention 
and therapy will help children with low IQ

What is already known? - Parents present in OPD with physical and psychological problems. They do not know the reasons behind them.

What does this study add? -Few physical and psychological problems are associated with low IQ Identification of them helps in early intervention. In psychological problems as the number of problems rises the chances of getting low IQ are more.

Conflict of interest : Nil

Source of funding : Nil

\section{REFERENCES}

[1] Yuping Z. Influence of Home Environment on Children's Schooling: From Teacher's Perspective. Gansu Survey of Children and Families. 2011

[2] American Academy of Pediatrics. Committee on Public Education. American Academy of Pediatrics: Children, Adolescents and Television. Pediatrics 2001:107:423-26

[3] Lawrence AS, Vimala A. School Environment and Academic Achievement of Standard IX Students. Journal of Educational \& Instructional Studies in the World. 2012; 2(3): 210-5

[4] Coon H, Carey G, Fulker DW, Defries JC. Influences of School Environment on the Academic Achievement Scores of Adopted and Non -adopted Children. Intelligence. 1993; 17: 79-104

[5] Screen KE. The Influence of Child-Parent and ChildTeacher relationships on the academic performance of children aged 10-12 Years. Children's Relationships and Academic Performance. 2011

[6] Shah H. Psychosocial aspects of academic failure in children. Health Administer.17;34-7

[7] Yi-Lung K. The impact of psychosocial factors on achievement gains between eighth and tenth grade. University of Iowa. 2011

[8] Gale CR, Hatch SL, Batty GD, Deary IJ. Intelligence in childhood and risk of psychological distress in adulthood: The 1958 National Child Development Survey and the 1970 British Cohort Study. Intelligence. 2009;37(6):592-9

[9] Gale CR, Deary IJ, Boyle SH, Barefoot J, Mortensen LH, Batty GD. Cognitive ability in early adulthood and risk of 5 specific psychiatric disorders in middle age: the Vietnam Experience Study. Arch Gen Psychiatry. 2008;65:1410-18

[10] Gale C, Batty G, Tynelius P, Deary I, Rasmussen F. Intelligence in Early Adulthood and Subsequent Hospitalization for Mental Disorders. Epidemiology. 2010;21:70-7

[11] Batty GD, Whitley E, Deary IJ, Gale CR, Tynelius P, Rasmussen F. Psychosis alters association between IQ and future risk of attempted suicide: cohort study of 1 109475 Swedish men. BMJ. 340 Article No: c2506.

[12] Osler M, Nybo Andersen AM, Nordentoft M. Impaired childhood development and suicidal behaviour in a cohort of Danish men born in 1953. J Epidemiol Community Health. 2008;62:23-28

[13] Gunnell D, Magnusson PKE, Rasmussen F. Low intelligence test scores in 18-year-old men and risk of suicide: cohort study. BMJ. 2004;330:167-170
[14] Andersson L, Allebeck P, Gustafsson JE, Gunnell D. Association of IQ scores and school achievement with suicide in a 40-year follow-up of a Swedish cohort. Acta Psychiatr Scand. 2008;118:99-105

[15] Fergusson DM, Horwood LJ, Ridder EM. Show me the child at seven II: childhood intelligence and later outcomes in adolescence and young adulthood. J Child Psychol Psychiatry. 2005; 46:850-858.

[16] Martin LT, Kubzansky LD, LeWinn KZ, Lipsitt LP, Satz P, Buka SL. Childhood cognitive performance and risk of generalized anxiety disorder. Int $\mathrm{J}$ Epidemiol. 2007;36(4):769-775

[17] Weitzman M, Gortmaker S, Sobol A. Maternal Smoking and Behavior Problems of Children. Pediatrics. 1992;90(3):342-349.

[18] Robert H. Bradley, Leanne Whiteside et al. Maternal IQ, the Home Environment, and Child IQ in Low Birthweight, Premature Children, Volume: 16 issue: 1, page(s): 61-74, March 1, 1993.

[19] Janice M Buelow, Joan K Austin et al, Behavior and mental health problems in children with epilepsy and low IQ, Dev Med Child Neurol. 2003 Oct; 45(10): 683-692.

[20] David AS, Malmberg A, Brandt L, Allebeck P, Lewis G. IQ and risk for schizophrenia: a populationbased cohort study. Psychol Med. 1997;27(6):13111323.

[21] Gunnell D, Harrison G, Rasmussen F, Fouskakis D, Tynelius P. Associations between premorbid intellectual performance, early-life exposures and early-onset schizophrenia: cohort study. $\mathrm{Br} \mathrm{J}$ Psychiatry. 2002;181:298-305

[22] Zammit S, Allebeck P, David AS, Dalman C, Hemmingsson T, Lundberg I, Lewis G. A longitudinal study of premorbid IQ Score and risk of developing schizophrenia, bipolar disorder, severe depression, and other nonaffective psychoses. Arch Gen Psychiatry. 2004;61(4):354-360

[23] Osler M, Lawlor DA, Nordentoft M. Cognitive function in childhood and early adulthood and hospital admission for schizophrenia and bipolar disorders in Danish men born in 1953. Schizophr Res. 2007;92(1-3):132-141.

[24] Koenen KC, Moffitt TE, Poulton R, Martin J, Caspi A. Early childhood factors associated with the development of post-traumatic stress disorder: results from a longitudinal birth cohort. Psychol Med. 2007;37(2):181-192

[25] Kremen WS, Koenen KC, Boake C, Purcell S, Eisen SA, Franz CE, Tsuang MT, Lyons MJ. Pretrauma cognitive ability and risk for posttraumatic stress disorder: a twin study. Arch Gen Psychiatry. 2007;64 (3):361-8

[26] Martin LT, Kubzansky LD, Lewinn KZ, Lipsitt LP, Satz P, Buka SL. Childhood cognitive performance and risk of generalized anxiety disorder. Int $\mathrm{J}$ Epidemiol. 2007;36(4):769-775.

[27] Osler M, Nordentoft M, Andersen AM. Childhood social environment and risk of drug and alcohol abuse in a cohort of Danish men born in 1953. Am J Epidemiol. 2006;163(7):654-61.

[28] Fergusson DM, Horwood LJ, Ridder EM. Show me the child at seven II: Childhood intelligence and later outcomes in adolescence and young adulthood. J Child Psychol Psychiatry. 2005;46(8):850-8 